\title{
Dendê: do cultivo da palma à produção de biodiesel
}

\author{
Dende: palm crops to biodiesel production \\ Michael Feroldi', Paulo André Cremonez ${ }^{2}$, Andressa Estevam ${ }^{3}$ \\ 1,2,3 Universidade Estadual do Oeste do Paraná
}

\section{Resumo}

A necessidade pelo desenvolvimento de fontes alternativas de energia garantindo uma segurança energética é a perspectiva dos países em desenvolvimento como o Brasil. A produção nacional de oleaginosas é vista como uma das saídas para complementação da atual matriz energética brasileira, sendo o óleo de dendê de grande interesse na conversão e produção de biodiesel. O presente trabalho tem por objetivo recolher e expor informações técnicas relativas à cultura do dendê, avaliando-se o potencial do óleo da planta quando voltada para a produção de biodiesel. Com um percentual de $20-22 \%$ de óleo de palma e um rendimento de 4-6 t/ha/ano, a palma é considerada como maior fonte de óleo para consumo no mundo, o que mostra um alto potencial para produção de biodiesel, que ainda pode aumentar seguindo manejos e zoneamento alternativos, superando ainda mais a tradicional cultura da soja. O biodiesel de dendê pode ser facilmente obtido em rota metílica básica em razão molar álcool/óleo de $6: 1$ à $60^{\circ} \mathrm{C}$, por $60 \mathrm{~min}$, atendendo as especificações americanas, europeias e brasileiras.

Palavras-chaves: Elaeis guineensis L., Biocombustíveis, Culturas energéticas.

\begin{abstract}
The necessity for developing alternative energy sources ensuring a energy security is the perspective of developing countries like Brazil. The national production of oilseeds is seen as one of the solutions to complement the current Brazilian energy matrix, palm oil being of great interest in the conversion and biodiesel production. The present paper aims to collect and expose technical information relating to the culture of oil palm, evaluating the potential of the oil of the plant when oriented to biodiesel production. With a percentage of $20-22 \%$ of palm oil and a yield of 4-6 t/ha/year, the palm is considered as the largest source of oil consumption in the world, which shows a high potential for biodiesel production, that can still increase following managements and zoning alternative, exceeding even more that traditional soybean crop. Biodiesel from palm oil can be easily obtained in methyl route basic with molar ratio alcohol/oil of $6: 1$, at $60^{\circ} \mathrm{C}$ for 60 min, meeting the American, European and Brazilian specifications.
\end{abstract}

Keywords: Elaeis guineensis L., Biofuels, Energy crops. 


\section{INTRODUÇÃO}

A década de 70, marcada principalmente pela crise mundial do petróleo, evidenciou a criação de programas de incentivo ao uso de energias renováveis como combustível no Brasil. As criações do Pro-álcool e posteriormente na década de 80, o Pro-óleo (Programa Nacional de Produção de Óleos Vegetais para Fins Energéticos), foram necessárias frente à importação brasileira de petróleo que na época representava $80 \%$ do consumo interno (CÉSAR \& BATALHA, 2010).

O Pro-óleo teve como objetivo principal o incremento de $30 \%$ de biodiesel no petrodiesel sendo que seus estudos iniciais empregaram soja (Glycine max), colza (Brassica spp.), girassol (Helianthus spp.) e dendê (Elaeis oleifera) (IICA, 2007). Porém, segundo Pousa et al. (2007), a queda do preço do petróleo iniciada em 1986 levou o programa ao abandono.

Na tentativa de inserir um programa de incentivo à produção de biodiesel, o governo, através do Ministério de Ciência e Tecnologia lançou o Programa Nacional de Produção e Uso de Biodiesel em 2004, considerando que a introdução na matriz energética garantisse a inclusão social e econômica, principalmente em função da agricultura familiar (CÉSAR \& BATALHA, 2010).

A palma (Elaeis guineensis Jacq.), popularmente chamada de dendê, é de origem africana tendo como centro específico de origem, a região do Golfo da Guiné. Introduzida na Bahia no final do século XVI no período de tráfico de escravos africanos, a cultura não teve obstáculos frente às condições climáticas da região, por serem bastante semelhantes do centro de origem, sendo posteriormente levada à região amazônica, onde se predominam as maiores áreas cultivadas (VENTURIERI et al., 2009).

Sua produção de óleo foi superior a 50 milhões de toneladas no ano de 2012, em aproximadamente 15 milhões de hectares plantados, superando a produção mundial de óleo de soja que não alcançou 42 milhões de toneladas (FAO, 2013), consagrando a cultura da palma como a principal fonte mundial de óleo vegetal. Ramalho Filho (2010) afirma que tal produção ainda pode aumentar baseando-se no zoneamento agroecológico proposto.

Desta forma, o presente trabalho ter por objetivo recolher e expor informações técnicas relativas ao manejo e cultivo do dendê, avaliando-se o potencial do óleo da planta voltado à produção de biodiesel.

\section{CARACTERÍSTICAS DA CULTURA}

O dendezeiro (Figura 1) é uma planta oleaginosa com até $15 \mathrm{~m}$ de altura, de ciclo perene, monocotiledônea e pertencente à família das Arecaceae (FERWERDA, 1975; CORLEY \& TINKER, 2003; RIBEIRO \& JUNIOR, 2010; PÁDUA, 2012). Por ser cultura perene de ciclo longo e de cultivo manual apresenta alta contribuição para o desenvolvimento social com a geração de empregos (PÁDUA, 2012).

Esta planta apresenta sistema radicular fasciculado, e por esta característica adapta-se bem em solos profundos, já que a maior parte das raízes se encontram entre 20 e $60 \mathrm{~cm}$ de profundidade, além de textura argilosa, boa drenagem e com pH entre 4,5 e 6 (RAMALHO FILHO, 2010; FERWERDA, 1975; LODY, 2009). As características químicas do solo são menos limitantes que as físicas, pela fácil adaptabilidade da cultura às medidas corretivas, desde que tomadas com precaução.

Devido sua característica monóica, o dendezeiro apresenta inflorescências masculinas e femininas na mesma planta, porém um dos sexos sempre permanece rudimentar com o desenvolvimento do outro (RAMALHO FILHO, 2010; SILVA, 2006), sendo influenciado pelas condições climáticas, visto que segundo Vargas (1978), períodos chuvosos caracterizam a formação de inflorescências femininas e as secas favorecem o desenvolvimento de inflorescências masculinas, ambas contendo milhares de flores, que podem ser visualizadas juntamente com os frutos e planta na Figura 1.

Assim como diversas leguminosas de clima temperado, a característica monóica da palma favorece a polinização entomófila (CONCEIÇÃO \& MULLER, 2000) tendo a abelha (Apis mellifera L.) como responsável por $80 \%$ da polinização das leguminosas (McGREGOR, 1976) enquanto o besouro Elaeidobius kamerunicus, originário de Camarões (África), se destaca mundialmente pelo aumento significativo da fecundação de dendezeiros (GENTY et al. 1986; HARUN \& NOOR, 2002; MOURA et al., 2008).

Com até $5 \mathrm{~cm}$ de comprimento e peso oscilando entre 3 e $30 \mathrm{~g}$, o fruto do dendezeiro é classificado como drupa do tipo séssil e elipsado, tendo sua espessura de endocarpo expressa por um gene 


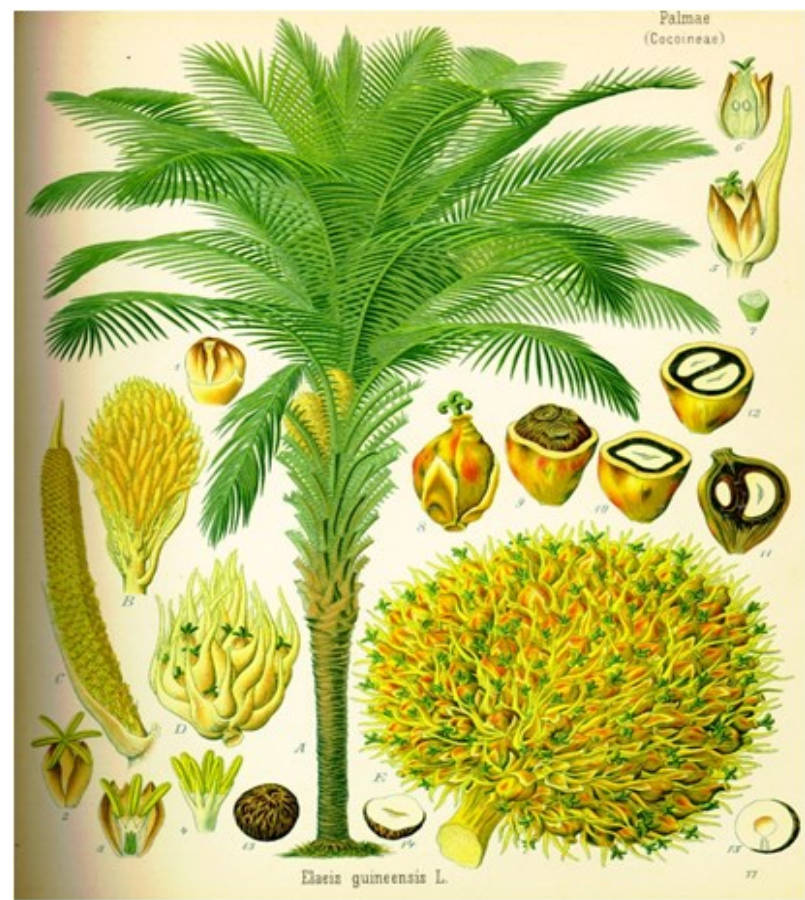

Figura 1 - Planta de dendezeiro, inflorescência e frutos (Fonte: VIRBOGA, 2013).

específico, que classifica o fruto como Psifera, Dura e Tenera (BARCELOS et al., 2000; SAMBANTHAMURTHI et al., 2000).

Segundo Portela (2007), três variedades de dendê são reportadas na literatura, classificadas de acordo com a espessura do endocarpo: Psifera, com fruto marcante pela ausência de casca protetora da amêndoa; Dura, que apresenta casca com pelo menos $2 \mathrm{~mm}$ de espessura; e Tenera, com espessura da casca inferior a $2 \mathrm{~mm}$, resultante do intercruzamento das variedades anteriores.

Segundo MAPA (2011), o mesocarpo contém em torno de $20-22 \%$ de óleo (palma) enquanto que a amêndoa pode alcançar um teor de até $55 \%$ de óleo (palmiste). Isto comprova a superioridade em relação ao teor na cultura da soja em diversas linhagens, que varia entre 16,58 e 20,75\%, confirmando um alto potencial para produção de biodiesel (BARBOSA et al., 2007; ESPINDOLA et al., 2008).

\section{CULTIVO E COLHEITA DA CULTURA}

A palma apresenta potencial produtivo elevado, com custo de produção inferior às principais oleaginosas (ZIMMER, 2010), sendo considerada a cultura responsável por suprir a demanda mundial de óleo vegetal no futuro (CORLEY, 2009).

Segundo Lody (2009), o dendezeiro destaca-se entre as oleaginosas por apresentar a maior produção de óleo por unidade de área. Além disso, produz dois óleos com caracterização visual e composições químicas diferentes, o da polpa, designado de óleo de palma, e o da amêndoa, chamado de óleo de palmiste (SAMBANTHAMURTHI et al., 2000). O primeiro marcado por sua cor avermelhada reservada à presença de carotenoides, e sua utilização na alimentação (POKU, 2002), e o segundo pela sua utilização no setor cosmético e farmacêutico (SEAGRI, 2013), tendo o uso do óleo na Nigéria como amenizante de infecções (UGBOGU et al., 2006).

O plantio da palma deve ser conduzido em terrenos com declividade inferior a $10 \%$ para facilitar as operações necessárias como tratos e manejo da cultura, respeitando também um espaçamento de $9 \mathrm{x}$ 7,8 m baseando-se nos vértices de um triângulo equilátero de aresta 9 m (SEAGRI, 2013; MDA, 2007). É recomendável, também, que a época de plantio coincida com o período de chuvas (MÜLLER, 1980).

Segundo os mesmos autores, recomenda-se a consorciação com leguminosas, no intuito de combater plantas daninhas, reduzir a compactação e erosão do solo, melhorar a fixação de nitrogênio 
e possibilitar renda extra no caso de culturas anuais.

$\mathrm{O}$ cultivo do dendê requer algumas exigências como temperatura média entre 24 e $30^{\circ} \mathrm{C}$ para melhores rendimentos (LODY, 2009). Por ser uma planta heliófila, normalmente se desenvolve melhor com incidência solar de 1.500 a 2.000 horas por ano além de pluviosidade média de $1.800 \mathrm{~mm}$ regularmente distribuídos durante o ano (BASTOS et al., 2001).

Devido às características físicas da planta, o dendezeiro demanda colheita manual, e segundo MDA (2007), o rendimento ideal por trabalhador, situa-se na faixa de 2 toneladas de cachos por dia, os quais devem ser processados em um intervalo de no máximo 24 horas no intuito de garantir qualidade e máxima quantidade de óleo.

Segundo Becker (2010), a produção do dendezeiro é relacionada com sua idade, aumentando até os 8 primeiros anos, quando se estabiliza e inicia-se o decrescimento gradual. Este mesmo autor trás que a colheita deve ser imediata ao seu amadurecimento, isto, pois a liberação de ácidos graxos é iniciada, o que geralmente compromete a qualidade do óleo (MÜLLER, 1980).

Portanto, segundo Barreto (2008), é imprescindível o cuidado com o intervalo entre a colheita e o processamento dos cachos visando à qualidade do óleo, sendo que a liberação de ácidos graxos livres que ocorre pela ação enzimática pode inviabilizar a produção de biodiesel por facilitar a formação de sabão, no caso de catálise básica.

Diferentes métodos podem ser empregados para extração de óleo de dendê, mas o mecânico, por simples prensagem e esmagamento dos frutos tem sido o mais reportado (PARENTE et al., 2003; KALTNER et al., 2004; SLUSZZ \& MACHADO, 2006; MDA, 2007; RAMALHO FILHO, 2010).

Além dos frutos, tem-se como subproduto do cultivo os cachos vazios que podem ser utilizados como adubo orgânico de lavouras de subsistência devido sua riqueza em potássio. Após extração do óleo, a polpa apresenta fibras que podem ser destinadas a alimentação de caldeiras a vapor, sendo que a casca também possui alto poder calorífico, tendo emprego como matéria-prima na indústria de carvão (SLUSZZ e MACHADO, 2006).

\section{4 ÓLEO DE DENDÊ E PRODUÇÃO DE BIODIESEL}

O óleo de dendê é visto como benéfico na alimentação humana por apresentar redução do colesterol sérico sanguíneo (LDL) e aumento do índice de HDL, apresentando características oxidantes exploradas na prevenção de doenças cardíacas e câncer (AGROPALMA, 2002; SEAGRI, 2013). Além disso, possui fitonutrientes como tocoferol, tocotrienol, carotenóide, sitosterol e esteróis (ONG et al., 2012).

O ácido palmítico, ácido oléico e ácido linoléico são os principais ácidos graxos que compõe o óleo de dendê, enquanto o óleo de amêndoa de palma é rico em ácido láurico, e é semelhante ao óleo de coco. Quase $90 \%$ do óleo de palma do mundo são usados para fins comestíveis (SAMBANTHAMURTHI et al., 2000). O perfil de ácidos graxos da polpa do dendê pode ser visualizado na Tabela 1.

Tabela 1 - Perfil de ácidos graxos do óleo da polpa do fruto de dendê

\begin{tabular}{ccc}
\hline Ac. Graxo & \multicolumn{2}{c}{$\%$} \\
\hline & Sambanthamurthi et al. (2000) & Rogério et al. (2012) \\
\hline $12: 0$ & 0,3 & - \\
$14: 0$ & 1,1 & 0,5 \\
$16: 0$ & 43,5 & 34,0 \\
$16: 1$ & 0,2 & 0,1 \\
$18: 0$ & 4,3 & 8,2 \\
$18: 1$ & 39,8 & 44,3 \\
$18: 2$ & 10,2 & 11,8 \\
$18: 3$ & 0,3 & 0,3 \\
$20: 0$ & 0,2 & 0,4 \\
\hline
\end{tabular}


Conforme o Malaysian Palm Oil Concil (MPOC), quando comparado com outras oleaginosas, o óleo de palma é disparado o mais vantajoso pela baixa necessidade energética para produção. Assim sendo, o balanço energético da cultura é responsável por uma relação produção/consumo de 9,5, demandando 19,2 GJ por ha/ano na produção de $1 \mathrm{~L}$ de óleo, disponibilizando na soma de seus subprodutos 182,1 GJ, bastante expressivo se comparado à relação produção/consumo 2,5 da soja (MPOC, 2013).

Rocha (2007) reportou que a produtividade de óleo de palma é a maior do mundo, até 10 vezes superior à produtividade de óleo de soja, com rendimentos variando de $4 \mathrm{a} 6 \mathrm{t} / \mathrm{ha} /$ ano justificando a utilização para a produção de biodiesel.

O uso de óleo de dendê in natura como combustível já é citado em 1920, sendo uma das primeiras referências ao uso dos ésteres derivados desse óleo em 1942 (SHAY, 1993). O processo de conversão em ésteres deste material garante maior fluidez e características mais próximas dos combustíveis fósseis comumente utilizados na época.

Um dos principais aspectos na seleção da matéria-prima para produção de um combustível alternativo é o seu balanço energético. Refere-se diretamente à relação do resultado favorável entre a energia consumida no decorrer da cadeia produtiva do combustível e a energia a produzida pelo mesmo. $\mathrm{Na}$ produção do etanol de cana de açúcar, 8,3 unidades de energia são produzidas para cada unidade de energia consumida na sua produção. Para efeito de comparação, o etanol produzido nos Estados Unidos apresenta uma relação de apenas 1,3:1. No Brasil, pesquisas realizadas em torno do biodiesel apontaram uma relação de 1,4 na cadeia produtiva da soja, 4,2 unidades para a cadeia produtiva da macaúba e de aproximadamente 5,6 unidades de energia produzidas para o dendê, confirmando o grande potencial das palmáceas como matéria-prima para o biodiesel (MACEDO e NOGUEIRA, 2005).

Em pesquisa realizada na Malásia, o balanço energético é positivo com 3,53 unidades geradas para a cultura da palma, contra apenas 1,44 obtido a partir do cultivo do óleo de colza (YEE et al., 2009).

Pesquisa em Bangkok utilizando biodiesel de palma e biodiesel de petróleo em motocicleta mostrou que não houve diferença significativa com relação às emissões entre os dois combustíveis. Além disso, o desempenho e o consumo de combustível foram os mesmos para os dois materiais (CHEENKACHOM \& FUNGTAMMASAN, 2010). Trabalho realizado por JAIRUROB et al. (2013), através de catálise alcalina reativa $(3,85 \% \mathrm{KOH} \mathrm{m} / \mathrm{v})$, obteve-se rendimentos de reação de $97,5 \%$ em peso de biodiesel por peso de óleo utilizado. O biodiesel gerado se enquadrou nos padrões europeus propostos para utilização do combustível em veículos automotivos.

Algumas das características do biodiesel produzido a partir do óleo de palma, via rota metílica alcalina podem ser visualizada na Tabela 2. A partir de trabalho de Ali e Tay (2013), que teve como relação ideal de óleo de dendê e álcool igual a 6:1 em mols com reação de 60 minutos a temperaturas de $60^{\circ} \mathrm{C}$, comprovou-se que o biodiesel produzido foi caracterizado por obter propriedades enquadradas nas especificações internacionais de qualidade para utilização e comercialização de biodiesel.

Tabela 2 - Propriedades dos ésteres metílicos de óleo de palma (EMOP) comparado com limites estipulados pelas normas americanas (ASTM) e européias (EN)

\begin{tabular}{ccccc}
\hline Análise & EMOP & ASTM D6751 & EN 14214 & ANP 14 \\
\hline Densidade $\left(\mathrm{kg} \cdot \mathrm{m}^{-3}\right)$ & 876 & $870-900$ & $860-900$ & $850-900$ \\
Viscosidade Cinemática $\left(\mathrm{mm}^{2} . \mathrm{s}^{-1}\right)$ & 4,76 & $1,9-6,0$ & $3,5-5,0$ & $3,0-6,0$ \\
Número de cetanos & 62,8 & $>47$ & $>51$ & - \\
Ponto de Fulgor $\left({ }^{\circ} \mathrm{C}\right)$ & 170 & $>130$ & $>120$ & $>100$ \\
Ponto de Névoa $\left({ }^{\circ} \mathrm{C}\right)$ & 13 & - & - & - \\
Ponto de Fluidez $\left({ }^{\circ} \mathrm{C}\right)$ & 17 & - & - & - \\
Índice de Saponificação $\left(\mathrm{mg} \cdot \mathrm{L}^{-1}\right)$ & 206,95 & - & - & - \\
\hline
\end{tabular}

Fonte: Adaptado de ALI e TAY (2013). 
Em pesquisa de Cukalovic et al. (2013), o biodiesel produzido através do óleo de dendê por rota metílica alcalina foi catalisado por metilato de potássio, garantindo rendimento do processo de $93 \%$. Os ésteres gerados apresentam boa qualidade e se enquadram nos padrões estabelecidos por normas européias garantindo melhores características lubrificantes que o diesel derivado do petróleo.

Os resíduos lipídicos do processo de produção e refino do óleo de dendê, também podem ser destinados à produção de biodiesel. A quantidade de impurezas como água e ácidos graxos livres dificulta o processo de transesterificação catalítica básica. No entanto, a utilização de reações supercríticas sem emprego de catalisadores apresenta bons rendimentos (até $80 \%$ ), com produção de ésteres de qualidade a um custo reduzido devido ao baixo valor da matéria prima empregada (TAN et al., 2012).

O Biodiesel produzido do óleo de dendê foi reportado por MIC (1985) apresentando um poder calorífico de $9.530 \mathrm{kcal}^{\mathrm{kg}}{ }^{-1}$, no caso de rota etílica, podendo ser ainda superior em caso de emprego de rota metanólica.

\section{CONCLUSÕES}

Com o presente estudo pode-se concluir que o óleo de dendê apresenta grande potencial na produção de biodiesel, tanto devido à sua alta produção por unidade de área e elevado balanço energético positivo se comparado a outras oleaginosas, quanto pelas características observadas no biodiesel produzido se assemelhando muito ao diesel convencional. Esta cultura pode representar um passo para o desenvolvimento da agricultura familiar principalmente em áreas de solo pobre e degradado visto a baixa exigência da cultura.

\section{REFERÊNCIAS}

AGROPALMA. Óleo de palma: um produto natural. Documento interno. Controle de Qualidade Industrial, 2002. 14 p.

ALI, E. N.; TAY, C. I. Characterization of Biodiesel Produced from Palm Oil via Base Catalyzed Transesterification. Procedia Engineering, v.53, p.7-12. 2013.

BARBOSA, D. M.; NAOE, L. K.; ZUNIGA, A. D. G. Avaliar o teor de lipídios em sementes de soja cultivadas no Estado de Tocantins. In: $14^{\circ}$ Jornada de Iniciação Científica da Unitins. Anais... UNITINS, PalmasTO, p.32-37. 2007.

BARCELOS, E.; NUNES, C. D. M.; CUNHA, R. N. V. Melhoramento genético e produção de sementes comerciais de dendezeiro. In: Viégas, I. de J. M.; MÜLLER, A. A. A cultura do dendezeiro na Amazônia Brasileira. Belém: Embrapa Amazônia Oriental/Manaus, p. 145-174, 2000.

BARRETO, E. J. F. Tecnologias de energias renováveis. Soluções energéticas para a Amazônia. $1^{a}$ ed. Brasília: Ministério de Minas e Energia (MME), 2008.

BASIRON, Y.; DARUS, A. The oil palm industry - from pollution to zero waste. In: 1st Global 500 Forum International Conference, 17-20 October, Kuala Lumpur; Malaysia; 1995; Kuala Lumpur; 1996; 141-165p.

BASTOS, T. X.; MÜLLER, A. A.; PACHECO, N. A. et al. Zoneamento de riscos climáticos para a cultura do dendezeiro no estado do Pará. Revista Brasileira de Agrometeorologia, v.9, n.3, p.564-570. 2001.

BECKER, B. K. Recuperação de áreas desflorestadas da Amazônia: será pertinente o cultivo da palma de óleo (dendê)? Confins; 2010. Disponivel em: <http://confins.revues.org/6609> Acesso em: ago/2013.

CÉSAR, A. da S.; BATALHA, M. O. Biodiesel in Brazil: history and relevant policies. Journal of Agricultural Research, v.5, p.1147-1153. 2010. 
CHEENKACHOM, K.; FUNGTAMMASAN, B. Development of engine oil using palm oil as a base stock for four stroke engines. Energy, v.35, p.2552-6. 2010.

CONCEIÇÃO, H. E. O.; MULLER, A. A. Botânica e morfologia do dendezeiro. In: VIÉGAS, I. J. M.; MULLER, A. A. (Ed.). A Cultura do dendezeiro na Amazônia brasileira. Belém: Embrapa Amazônia Oriental, p. $31-44,2000$.

CORLEY, R. H. V. How much palm oil do we need? Environmental Science and Policy, v.12, p.134-139. 2009.

CORLEY, R. H. V; TINKER, P. B. H. The oil palm. Blackwell Science Ltd. 4a ed. Oxford. 2003.

CUKALOVIC, A.; MONBALIU, J. C. M.; EECKHOUT, Y.; ECHIM, C.; VERHÉ, R.; HEYNDERICKX, Y.; STEVENS, C. V. Development, optimization and scale-up of biodiesel production from crude palm oil and effective use in developing countries. Biomass and bioenergy, v.56, p.62-69. 2013.

ESPINDOLA, S. M. C. G.; CAVALCANTE, A. K.; GONÇALVES, D. A. R. et al. Avaliação do teor de óleos e da produtividade em linhagens de soja para cultivo no Cerrado. In: IX Simpósio Nacional Cerrado e II Simpósio Internacional Savanas Tropicais. Anais... Embrapa Brasília-DF. CD-ROM 1. 2008.

FERWERDA, J. D. Ecophysiology of the african oil palm. In: Alvim P. de (Coord.) Ecophysiology of tropical crops. Ilhéus: Ceplac v.2, p.1-49. 1975.

Food and agriculture organization of the United Nations. FAOSTAT: production oilcrops 2012. Disponível em: <http://faostat.fao.org/site/567/DesktopDefault.aspx?PageID=567\#ancor > Acesso em: ago/2013.

GENTY, P.; GARZON, A.; LUCCHINI, F.; DELVARE, C. Polinización entomófila de La palma africana en América tropical. Oléagineux, v.41, n.1, p.99-111. 1986.

HARTLEY, C. W. S. The oil palm (Elaeis guineensis Jacq.). Tropical Agriculture Series, 2o edition. Longman Group, p. 692-780, 1988.

HARUN, M. H.; NOOR, M. R. Fruit set and oil palm bunch components. Journal of Oil Palm Research, v.14, p.24-33. 2002.

IICA. Instituto Interamericano de Cooperação para a Agricultura. Informe sobre a Situação e Perspectivas da Agroenergia e dos Biocombustíveis no Brasil. 2007.

JAIRUROB, P.; PHALAKORNKULE, C.; NA-UDORN, A.; PETIRAKSAKUL, A. Reactive extraction of after-stripping sterilized palm fruit to biodiesel. Fuel, v.107, p.282-289. 2013.

KALTNER, F. J.; $\quad$ FURLAN JÚNIOR, J.; SILVA, E. B. da. et al. Viabilidade Técnica e Econômica de Produção de Ésteres de Óleo de Palma, para Utilização como Substituto de Óleo Diesel, na Amazônia. EMBRAPA - Documentos, 193, 2004.

LODY, R. G. da M. Dendê: símbolo e sabor da Bahia. Editora Senac São Paulo, 2009. 149p.

MACEDO, I. C.; NOGUEIRA, L. A. H. Biocombustíveis. Cadernos NAE / Núcleo de Assuntos Estratégicos da Presidência da República, n.2. Secretária de Comunicação de Governo e Gestão Estratégica, Brasília, 2005.

MAPA. Anuário Estatístico da Agroenergia - 2010. Brasília: Ministério da Agricultura, Pecuária e Abastecimento - Brasil, 2011. 160p.

McGREGOR, S. E. Insect pollination of cultivated crop plants. Washington: Agriculture Handbook, 1976. $411 \mathrm{p}$. 
MDA. Ministério de Desenvolvimento Agrário. Viabilidade de extração de óleo de dendê no Estado do Pará. Texto para revisão e crítica.UFV,Viçosa-MG, 2007.

MIC. Ministério da Indústria e do Comércio. Produção de Combustíveis Líquidos a Partir de Óleos Vegetais. Secretaria de Tecnologia Industrial. Coordenadoria de Informações Tecnológicas, Brasília-DF, 1985.

MOURA, J. I. L.; CIVIDANES, F. J.; SANTOS FILHO, L. P. dos. et al. Polinização do dendezeiro por besouros no Sul da Bahia. Pesq. Agropec. Bras., Brasília, v.43, n.3, p.289-294. 2008.

MPOC. Malaysian Palm Oil Council. Balanço energético positivo. Disponível em: <http://www.mpoc.org. my/The_Oil_Palm_Tree.aspx> Acesso em: ago/2013.

MÜller, A. A. A. Cultura do dendê. Belém. Centro de Pesquisa Aqropecuária do Trópico Úmido, EMBRAPA-CPATU, Miscelânea nº 5, 1980. 24p.

ONG, H. C.; MAHLIA, T. M I.; MASJUKI, H. H.; HONNERY, D. Life cycle cost and sensitivity analysis of palm biodiesel production. Fuel, v.98, p.131-139. 2012.

PÁDUA, M. S. Germinação in vitro, indução e caracterização de massas pró-embriogênicas de dendezeiro (Elaeis guineensis Jacq.). 2012. 120f. Dissertação (Mestrado em Biotecnologia Vegetal), Universidade Federal de Lavras. Lavras-MG.

PARENTE, V. de M.; OlIVEIRA JÚNIOR, A. da R.; COSTA, A. M. da. Projeto Potencialidades Regionais Estudo de Viabilidade Econômica: Dendê. Superintendência da Zona Franca de Manaus, 2003.

POKU, K. Small-scale palm oil processing in Africa. FAO Agricultural Services Bulletin, 148, 2002.

PORTELA, H. E. Avaliação técnico-econômica de um empreendimento produtivo de biodiesel. 2007. 208f. Dissertação (Mestrado em Gerenciamento e Tecnologias Ambientais no Processo Produtivo), Universidade Federal da Bahia. Salvador-BA.

POUSA, G. P. A. G.; SANTOS, A. L. F.; SUAREZ, P. A. Z. History and policy of biodiesel in Brazil. Energy Policy, v.35, n.11, p.5393-5398, 2007.

RAMALHO FILHO, A. Zoneamento agroecológico, produção e manejo da cultura de palma de óleo na Amazônia. EMBRAPA Solos, Rio de Janeiro-RJ, 2010.

RIBEIRO, V. C. N.; JUNIOR, R. A. G. Avaliação do crescimento foliar de híbridos interespecíficos de dendezeiro (Elais guineensis x Elais oleifera), em Mojú no estado do Pará. In: SEMINÁRIO DE INICIAÇÃO CIENTÍFICA DA EMBRAPA, 14., 2010, Belém, PA. Anais... Belém, PA: Embrapa Amazônia Oriental, 2010. 1 CD-ROM. PIBIC. 2010.

ROCHA, R. N. C. Culturas Intercalares para Sustentabilidade da Produção de Dendê na Agricultura Familiar. 2007. 75f. Tese (Doutorado em Fitotecnia), Universidade Federal de Viçosa. Viçosa-MG.

ROGÉRIO, J. B.; DUARTE, I. D.; et al. Produtividade de genótipos de palma cultivados no cerrado. In: $5^{\circ}$ Congresso da Rede Brasileira de Tecnologia de Biodiesel. Salvador-BA. Anais... $5^{\circ}$ Congresso, p.245-246. 2012.

SAMBANTHAMURTHI, R.; SUNDRAM, K.; TAN, Y. A. Chemistry and biochemistry of palm oil. Progress in Lipid Research, v.39, n.6, p.507-558. 2000.

SEAGRI - Secretaria da Agricultura. Irrigação e Reforma Agrária. Cultura de Dendê. 10p. Disponível em: <http://www.seagri.ba.gov.br/Dende.htm>. Acesso: ago/2013. 
SHAY, E. G.: Diesel fuel from vegetable oils: status and opportunities. Biomass and Bioenergy, n.4, p.227-242. 1993.

SILVA, J. S. de O. Produtividade de óleo de palma na cultura do dendê na Amazônia Oriental: influência do clima e do material genético. 2006. 65f. Dissertação (Mestrado em Fitotecnia), Universidade Federal de Viçosa. Viçosa-MG.

SLUSZZ, T.; MACHADO, J. A. D. Características das potenciais culturas matérias-primas do biodiesel e sua adoção pela agricultura familiar. An. 6. Enc. Energ. Meio Rural. 2006.

TAN, K. T.; LEE, K. T.; MOHAMED, A. R. Potential of waste palm cooking oil for catalyst-free biodiesel production. Energy, v.36, p.2085-2088. 2012.

UGBOGU, O. C.; ONYEAGBA, R. A.; CHIGBU, O. A. Lauric acid content and inhibitory effect of palm kernel oil on two bacterial isolates and Candida albicans. African Journal of Biotechnology, v.5, n.11, p.10451047. 2006.

VARGAS, P. F. Factores que afectan el crecimiento, floración y producción. In: VALLEJO, G.; FIGUEREDO, P.; ROJAS, L.; MUÑOZ, R.; MENA, E.; CRUZ, R.; GENTY, P.; SANCHES, A.; LOWE, J.; ARAGON, J. Palma Africana de aceite. Palmira: ICA,1978. 455p.

VENTURIERI, A.; FERNANDES, W. R.; BOARI, A. de J.; VASCONCELOS, M. A. Relação entre ocorrência do amarelecimento fatal do dendezeiro (Elaeis guineensis Jacq.) e variáveis ambientais no estado do Pará. In: Simpósio Brasileiro de Sensoriamento Remoto, Natal, INPE, p.523-530. 2009.

VIRBOGA - The Virtual Botanic Garden. 2013. Disponível em: <http://www.virboga.de/Elaeis_guineensis. htm> Acesso em: set./2013.

YEE, K. F.; TAN, K. T.; ABDULLAH, A. Z.; LEE, K. T. Life cycle assessment of palm biodiesel: revealing facts and benefits for sustainability. Applied Energy, v.86, p.189-96. 2009.

ZIMMER, Y. Competitiveness of rapeseed, soybeans and palm oil. Journal of Oilseed Brassica, v.1, n.2, p.8490. 2010. 